\title{
Hyaluronidase treatment of synovial fluid is required for accurate detection of inflammatory cells and soluble mediators
}

\author{
Hilde Brouwers ${ }^{{ }^{*}} \mathbb{0}$, Johannes Hendrick von Hegedus ${ }^{1}$, Enrike van der Linden², Rachid Mahdad ${ }^{3}$, \\ Margreet Kloppenburg ${ }^{1}$, René Toes ${ }^{1}$, Martin Giera ${ }^{4}$ and Andreea loan-Facsinay
}

\begin{abstract}
Background: Synovial fluid (SF) is commonly used for diagnostic and research purposes, as it is believed to reflect the local inflammatory environment. Owing to its complex composition and especially the presence of hyaluronic acid, SF is usually viscous and non-homogeneous. In this study, we investigated the importance of homogenization of the total SF sample before subsequent analysis.

Methods: SF was obtained from the knee of 29 arthritis patients (26 rheumatoid arthritis, 2 osteoarthritis, and 1 juvenile idiopathic arthritis patient) as part of standard clinical care. Synovial fluid was either treated with hyaluronidase as a whole or after aliquoting to determine whether the concentration of soluble mediators is evenly distributed in the viscous synovial fluid. Cytokine and IgG levels were measured by ELISA or Luminex and a total of seven fatty acid and oxylipin levels were determined using LC-MS/MS in all aliquots. For cell analysis, synovial fluid was first centrifuged and the pellet was separated from the fluid. The fluid was subsequently treated with hyaluronidase and centrifuged to isolate remaining cells. Cell numbers and phenotype were determined using flow cytometry.

Results: In all patients, there was less variation in IgG, 17-HDHA, leukotriene $B_{4}\left(L_{T B}\right)$, and prostaglandin $E_{2}\left(P_{G} E_{2}\right)$ levels when homogenization was performed before aliquoting the SF sample. There was no difference in variation for cytokines, 15-HETE, and fatty acids arachidonic acid (AA), eicosapentaenoic acid (EPA), and docosahexaenoic acid (DHA). Between 0.8 and 70\% of immune cells (median 5\%) remained in suspension and were missing in subsequent analyses when the cells were isolated from untreated SF. This percentage was higher for T and B cells: 7-85\% (median 22\%) and 7-88\% (median $23 \%$ ), respectively.
\end{abstract}

Conclusions: Homogenization of the entire SF sample leads to less variability in lgG and oxylipin levels and prevents erroneous conclusions based on incomplete isolation of synovial fluid cells.

Keywords: Synovial fluid, Hyaluronidase, Rheumatoid arthritis

\section{Background}

Synovial inflammation is a symptom of many rheumatic musculoskeletal diseases such as rheumatoid arthritis (RA), juvenile idiopathic arthritis (JIA), spondyloarthritis

\footnotetext{
*Correspondence: hildebrouwers@live.n

${ }^{1}$ Department of Rheumatology, Leiden University Medical Center (LUMC), Leiden, The Netherlands

Full list of author information is available at the end of the article
}

(SpA), osteoarthritis (OA), and systemic lupus erythematosus (lupus). Synovial joints contain a synovial lining (synovium) consisting primarily of synovial fibroblasts and a synovial cavity containing SF.

During inflammation, immune cells such as macrophages, lymphocytes, and neutrophils infiltrate the joint and SF accumulates. The cells and soluble mediators present at these local sites of inflammation are of interest original author(s) and the source, provide a link to the Creative Commons licence, and indicate if changes were made. The images or other third party material in this article are included in the article's Creative Commons licence, unless indicated otherwise in a credit line to the material. If material is not included in the article's Creative Commons licence and your intended use is not permitted by statutory regulation or exceeds the permitted use, you will need to obtain permission directly from the copyright holder. To view a copy of this licence, visit http://creativecommons.org/licenses/by/4.0/. The Creative Commons Public Domain Dedication waiver (http://creativeco mmons.org/publicdomain/zero/1.0/) applies to the data made available in this article, unless otherwise stated in a credit line to the data. 
to unravel disease pathophysiology and are therefore often studied.

Synovial fluid cytokines have been of interest for many years and more recently, lipid-derived inflammatory mediators were studied in RA and OA [1-6]. Next to the interest in soluble mediators, frequencies, and phenotype of specific $\mathrm{T}$ and $\mathrm{B}$ cell subsets, monocytes and NK cells were determined in a wide range of rheumatic musculoskeletal diseases [7-24]. In addition to experimental research, synovial fluid is also used for diagnostic purposes to obtain information about antigen-specific antibody levels or white blood cell (WBC) count [25-27].

Synovial fluid is often aspirated from the inflamed joints of arthritis patients to reduce discomfort and to make room to inject therapeutics or to perform diagnostics, as part of standard clinical care. Therefore, it is easier accessible for research than synovium, which can only be obtained via a more invasive procedure such as arthroplasty or synovial biopsy. Synovial fluid provides lubrication to the joint and acts as a transport medium for nutrients and cells. It consists of an ultrafiltrate of plasma containing many different proteins including high amounts of hyaluronan. Hyaluronan is produced by the synovial fibroblasts and is present in a $10^{5}$ higher concentration in synovial fluid compared to plasma [28]. Hyaluronan forms dense mesh networks in the synovial fluid, which make the fluid viscous. Due to this viscosity, handling synovial fluid in a laboratory setting is challenging. To overcome this problem, synovial fluid can be treated with hyaluronidase, which breaks down the dense mesh network of hyaluronan fibers. Indeed, a few reports, analyzing equine SF or SF from non-inflammatory conditions, have shown that technical issues can occur when analyzing untreated SF [29-31]. For instance, it was shown that treating SF with hyaluronidase before cytokine analysis improves cytokine recovery in a polystyrene, but not magnetic bead, Luminex assay [31]. In addition, hyaluronidase treatment is routinely performed before proteomic and metabolomic analysis as this is required to prevent clogging of the mass spectrometers $[5,32]$. However, to date there are no reports on the importance of hyaluronidase treatment as part of the standard processing protocol for SF and this treatment is therefore not routinely used in arthritis research. For example, hyaluronidase treatment is not mentioned in more than half of the abovementioned studies investigating SF immune cells in inflammatory joint diseases $[1,3$, $6-10,12-15,20,33]$. In daily practice, SF is collected, aliquoted, and stored before analysis to be able to analyze soluble mediators in multiple patients at once. Subsequently one aliquot per patient is then used to measure soluble mediators. However it is unclear whether the levels of soluble mediators are comparable between the aliquots when the aliquots were taken and stored before hyaluronidase treatment. Moreover the effect of hyaluronidase treatment on the recovery of cells from SF is unclear and there is no consensus whether inflammatory cells should be analyzed before or after hyaluronidase treatment.

In this study, we investigated whether homogenization of SF sample is required for the reproducibility of IgG, cytokine, and lipid measurements. In addition, we performed flow cytometric analysis on cells isolated from treated and untreated SF.

\section{Methods \\ Patients}

Synovial fluid was obtained via knee aspiration from 27 arthritis patients (26 rheumatoid arthritis and 1 juvenile idiopathic arthritis patient) visiting the rheumatology outpatient clinic of the LUMC as part of standard clinical care. Written informed consent was obtained from all these donors. Anonymized leftover synovial fluid of two osteoarthritis patients was collected using a syringe before knee-replacement surgery performed at the departments of orthopedic surgery at the LUMC and the Alrijne hospital in Leiden. The study was approved by the local ethical committee.

\section{Processing of synovial fluid for molecular measurements}

On the same day of knee aspiration, the fluid was divided in two sets of 3-5 aliquots ranging between $300 \mu \mathrm{L}$ and $1 \mathrm{~mL}$ to be able to fit the fluid in a heat block with vortex modus. $1 \mathrm{mg} / \mathrm{mL}$ hyaluronidase from bovine testis (Sigma-Aldrich) was added in a 1:11 ratio. Hyaluronidase was suspended just before use in phosphate-buffered saline (PBS, B.Braun). SF was vortexed for $5 \mathrm{~min}$ and subsequently incubated for $25 \mathrm{~min}$ at $37^{\circ} \mathrm{C}$. Next, the first set of aliquots (set 1 ) was directly centrifuged for 10 min at $931 \mathrm{xg}$, while the second set (set 2) was first pooled together before centrifugation. After centrifugation, the pooled set was divided again in 35 individual aliquots. Of each of the aliquots in set 1 and set $2,100 \mu \mathrm{L}$ supernatant was transferred to a glass vial (Agilent Technologies) together with $294 \mu \mathrm{L}$ methanol (Fluka LC-MS CHROMASOLV grade, Sigma-Aldrich) and $6 \mu \mathrm{L}$ internal standards $\left(50 \mathrm{ng} / \mathrm{mL}\right.$ leukotriene $\mathrm{B}_{4}-\mathrm{d} 4$, prostaglandin $\mathrm{E}_{2}-\mathrm{d} 4$, 15-HETE-d8, and $500 \mathrm{ng} / \mathrm{mL}$ of docosahexaenoic acidd5, all from Cayman Chemicals). Argon gas was added and the samples were stored at $-80^{\circ} \mathrm{C}$. Similarly, $200 \mu \mathrm{L}$ supernatant was also stored at $-20^{\circ} \mathrm{C}$ for immunoglobulin and IL-8 analysis. For IL-6, IL-10, CXCL1, CXCL5, and TNF $\alpha$ analysis, SF was centrifuged for $10 \mathrm{~min}$ at $931 \mathrm{xg}$ on the day of knee aspiration and supernatant was stored directly at $-80^{\circ} \mathrm{C}$. At the day of analysis, SF was 
thawed to room temperature and treated as described above for the fresh SF.

\section{ELISA}

Interleukin 8 (IL-8) and IgG ELISA were performed according to manufacturer's protocol (Invitrogen, BD Biosciences, and Bethyl Laboratories, respectively).

\section{Luminex}

Bio-Plex pro reagent kit III and Bio-Plex Pro Human IL-6 set (171BK29MR2), IL-10 set (171BK32MR2), TNF- $\alpha$ (171BK55MR2), CXCL1 (171BK22MR2), and CXCL5 (171BK14MR2) were purchased from Bio-rad. The cytokines and chemokines were determined according to the manufacturer's protocol. SF samples were measured on the Bio-Plex 200 system (Bio-Rad), and analysis was done using Bio-plex Manager 6.2 Software (Bio-Rad).

\section{Lipidomic analysis of synovial fluid}

LC-MS/MS-based lipid mediator and oxylipin profiling were carried out as described elsewhere [4]. A QTrap 6500 mass spectrometer (Sciex) was used, coupled to a Shimadzu Nexera LC30-system including auto-sampler and column oven (Shimadzu). The column was a Kinetex C18 $50 \times 2.1 \mathrm{~mm}, 1.7 \mu \mathrm{m}$, protected with a C8 pre-column (Phenomenex). LC-MS/MS peaks were integrated with manual supervision, and the areas were corrected to corresponding IS using MultiQuant ${ }^{\mathrm{TM}} 2.1$ (Sciex). For quantitation, the multiple reaction monitoring (MRM) transitions and collision energies (CE) were used together with calibration lines for quantification. Calibration lines were constructed using 15-HETE, 17R-HDHA, leukotriene $\mathrm{B}_{4}$, prostaglandin $\mathrm{E}_{2}$, arachidonic acid, docosahexaenoic acid, and eicosapentaenoic (Cayman Chemicals)

\section{Flow cytometry analyses of synovial fluid cells}

For general analysis, the fluid was centrifuged for 10 min at $931 \mathrm{xg}$ and cells were collected and analyzed. The supernatant was treated with hyaluronidase as stated above and subsequently centrifuged for $10 \mathrm{~min}$ at $931 \mathrm{xg}$ to isolate remaining cells. For the effect of hyaluronidase treatment on cell marker expression, the SF was diluted 20x in PBS and divided in two. One sample was treated with hyaluronidase (treated), and the other sample was treated similarly, but without the addition of hyaluronidase (untreated). Isolated cells were resuspended in PBS and filtered through a $70-\mu \mathrm{m}$ cell strainer before flow cytometry. For general cell characterization, cells were stained with anti-CD3 (AF700, clone UCHT1), antiCD14 (FITC, clone M5E2), anti-CD15 (APC, clone HI98), anti-CD16 (PE, clone B73.1), anti-CD19 (PerCp/Cy5.5, clone SJ25C1), and anti-CD45(APC/Cy7, clone 2D1). The gating strategy is depicted in supplementary figure 1.
For additional characterization into $\mathrm{CD} 4^{+} \mathrm{T}$ cells and $\mathrm{CD}^{+} \mathrm{T}$ cells, cells were stained with anti-CD3 (PE, clone SK7), anti-CD4 (APC, clone SK3), and anti-CD8 (FITC, clone SK1). For the effect of hyaluronidase treatment on cell marker expression, cells were stained with anti-CD3 (Pacific Blue, clone SK7), anti-CD4 (APC, clone SK3), anti-CD8 (FITC, clone SK1), anti-CD19 (APC/Cy7, clone SJ25C1), anti-CD44 (PE/Cy7, clone G44-26), and antiCD69 (PE/CF594, clone FN50). The positivity for CD44 and CD69 was determined using isotype controls IgG2bk (PE/Cy7, clone 27-35) and IgG1 (PE/CF594, clone X40). For additional characterization into naïve $\mathrm{B}$ cells, memory B cells and plasmablasts/cells, cells were stained with anti-CD3 (Pacific Blue, clone SK7), anti-CD14 (Pacific Blue, clone M5E2), anti-CD19 (APC/Cy7, clone SJ25C1), anti-CD20 (AF 700, clone 2H7), and anti-CD27 (PE/Cy7, clone M-T271). For gating strategy for the $\mathrm{T}$ cell and $\mathrm{B}$ cell subsets, see supplementary figure 2 .

All antibodies were from BD except for the anti-CD20 which was from Sony Biotechnology (USA, CA, San Jose). For all analysis, dead cells were excluded using DAPI (Molecular Probes) and cells were quantified using Flow count Fluorospheres (Beckman Coulter). Cells were measured on a LSR Fortessa (BD) and were analyzed with FACSDiva Software (BD).

\section{Statistical analyses and calculations}

Wilcoxon signed rank tests were performed to evaluate significance between groups in all figures. Coefficient of variation $(\mathrm{CV})$ was calculated by dividing the standard deviation of a group of measurements by the mean and expressing this as a percentage.

\section{Results}

Effect of hyaluronidase on soluble mediator measurements To test the whether the concentration of inflammatory soluble mediators is evenly distributed in viscous synovial fluid, we treated each synovial fluid as depicted in Fig. 1A. We also treated set 1 with hyaluronidase to exclude the possibility that the viscosity hampers soluble mediator detection as was shown before [31]. We measured CXCL1, CXCL5 IL-6, IL-8, IL-10, TNF $\alpha$, and total IgG levels in the aliquots of set 1 and set 2 in eight arthritis patients. Levels of the cytokines differed considerably between patients (Fig. 2A-E). The data of CXCL5 is not shown as this mediator was only detected in two out of eight patients. To assess intra-assay variation, the $\mathrm{CV}$ was calculated for each set of aliquots of the patients with detectable soluble mediator levels. There was no difference in CV between the two sets of samples for CXCL1, IL-6, IL-8, IL-10, TNF $\alpha$ (Fig. 2B). IgG levels were stable between the different patients and in contrast to the cytokines, hyaluronidase treatment before aliquoting 


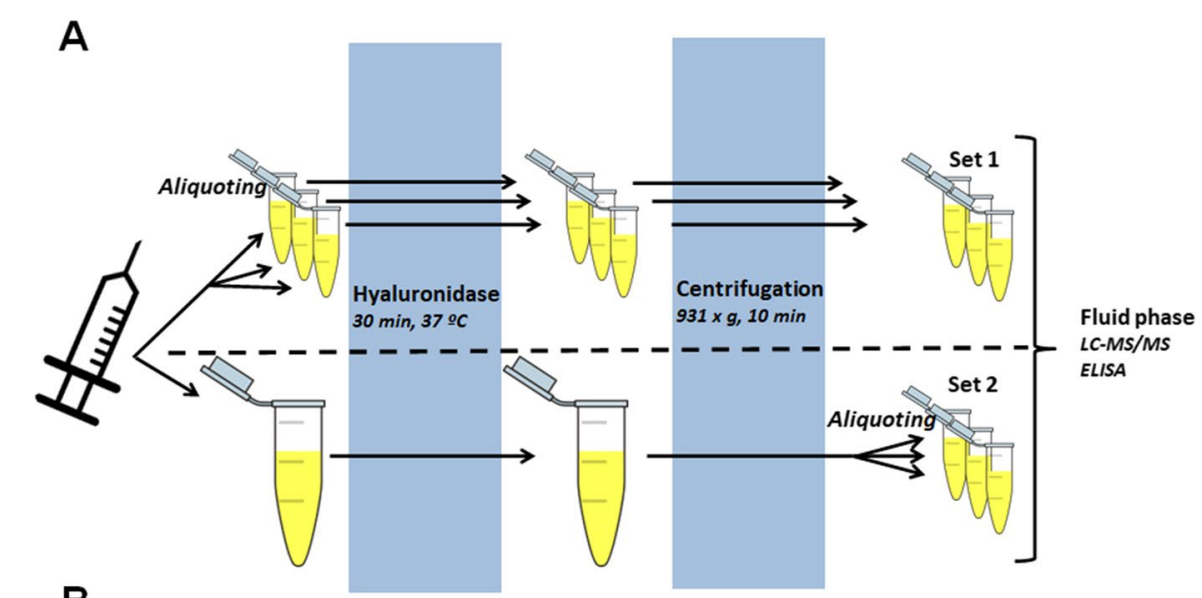

B

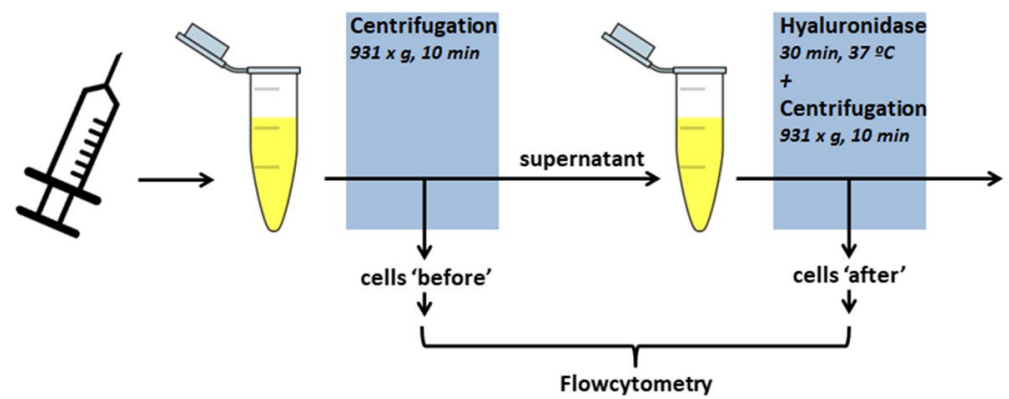

Fig. 1 Schematic overview of the experimental setup. A Half of the synovial fluid was divided into aliquots while the other half was kept as a whole. The SF was treated with hyaluronidase after which it was centrifuged. Set 1 was kept as separate aliquots during the whole procedure and set 2 was divided in aliquots directly after centrifugation. B Synovial fluid was centrifuged and the pelleted cells are the "before" cells. The supernatant was treated with hyaluronidase and subsequently centrifuged. The pelleted cells are the "after" cells

resulted in lower CVs for IgG measurements (Fig. 2F, L). In addition to measurements of large protein structures as cytokines and antibodies, we investigated small molecules, such as fatty acids and oxidized lipids (Fig. 3AC). Hyaluronidase treatment before aliquoting did not improve CV values for AA, DHA, and EPA (Fig. 3D). These fatty acids can be converted to monohydroxylated fatty acids such as 15-HETE and 17-HDHA, derived from AA and DHA, respectively. Hydroxylated products can in turn be converted to highly bioactive oxylipids like $\mathrm{PGE}_{2}$ and $\mathrm{LTB}_{4}$. In contrast to the $\mathrm{CV}$ values of fatty acids, the values for $17-\mathrm{HDHA}$ and $\mathrm{LTB}_{4}$ improved significantly when fluids were treated with hyaluronidase before aliquoting (Fig. 3E, F).

\section{Cellular measurements benefit from hyaluronidase treatment}

We hypothesize that the viscosity of SF impairs the recovery of immune cells during isolation. To test this, readily-accessible cells (before fraction) were first isolated from SF by centrifugation. Thereafter, the supernatant, i.e., hyaluronan-rich fraction (after fraction), was treated with hyaluronidase and centrifuged again, to isolate remaining cells (Fig. 1B). Depending on the patient, up to $70 \%$ of the $\mathrm{CD} 45^{+}$cells could be isolated from the supernatant after hyaluronidase treatment (Fig. 4A). This percentage did not correlate with the total number of cells present in the fluid (Fig. 4B). Interestingly, mostly $\mathrm{T}$ and $\mathrm{B}$ cells were recovered from the hyaluronan-rich (after) fraction (Fig. 4C). Further characterization of $\mathrm{T}$ cell subsets revealed no difference in $\mathrm{CD}^{+}$or $\mathrm{CD}^{+} \mathrm{T}$ cell percentages between the before and after fractions (Fig. 4D). Surprisingly, however, the cells in the after fraction displayed a less activated phenotype, reflected by a lower expression of $\mathrm{CD}^{+} 9^{+}$(Fig. 4E). This effect was primarily observed in the $\mathrm{CD}^{+}{ }^{+} \mathrm{T}$ cells (Fig. 4F). There was no difference in the percentage of $\mathrm{CD} 9^{+}$cells in $\mathrm{CD}^{+}, \mathrm{CD} 4^{+}$, or $\mathrm{CD} 8^{+}$ $\mathrm{T}$ cells between the before and after samples (data not shown). The hyaluronidase treatment itself does not affect CD69 expression (Supplementary figure 3B). We could not detect any differences in either naïve $\mathrm{B}$ cell, 


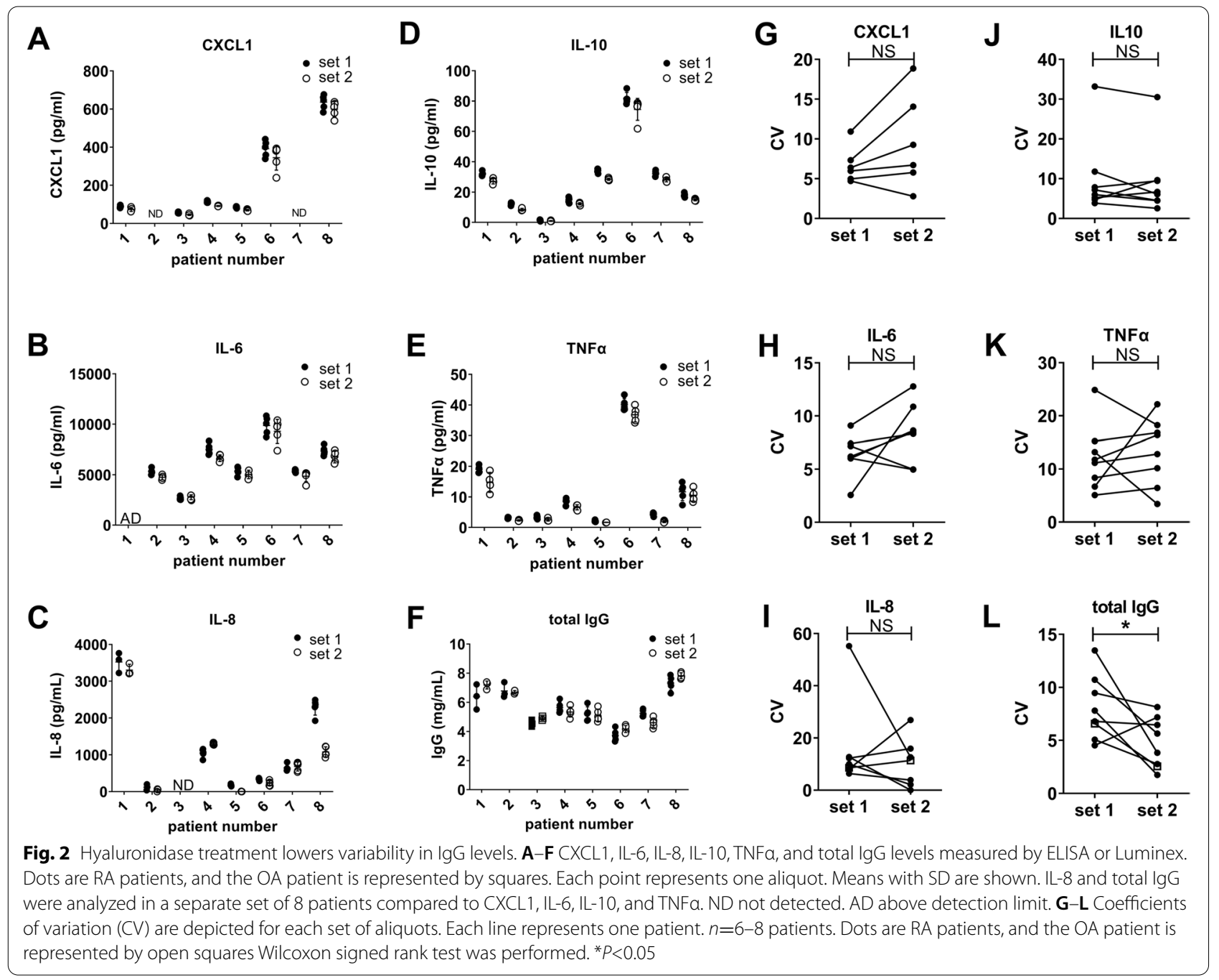

memory B cell, or plasmablast/plasmacell percentages between the fractions (Fig. 4G).

\section{Smaller immune cells are retained in the hyaluronan-rich supernatant}

To gain more insight into the possible mechanism underlying the retention of certain lymphocytes in the hyaluronan mesh, we investigated expression of the hyaluronan receptor $\mathrm{CD} 44$ and the size of the immune cells in the SF supernatant [34]. We hypothesized that cells with a higher expression of CD44 could be preferentially retained in the untreated SF. However, there was no difference in CD44 expression on lymphocytes and neutrophils (Fig. 5A-C). In control experiments, the hyaluronidase treatment itself did not affect CD44 expression (Supplementary figure 3A). Interestingly, smaller cells are preferentially retained in the untreated SF (Fig. 5D).

\section{Discussion}

Hyaluronidase treatment of SF is not routinely used in rheumatology research; however, our results show the critical importance of homogenization of the synovial fluid sample to obtain reproducible and accurate immunological measurements. We show that IgG titers, 17-HDHA levels, and pro-inflammatory $\mathrm{LTB}_{4}$ levels become significantly less variable when SF is treated with hyaluronidase before aliquoting. In addition, hyaluronidase treatment of SF prior to cell isolation highly increased isolated cell numbers and therefore positively affects the accuracy of subsequent cell analysis.

Several joint diseases are characterized by the presence of auto-antibodies such as RF and ACPA in RA and ANA and anti-dsDNA antibodies in SLE $[25,26]$. However, the mere presence of the autoantibodies in circulation does not directly indicate a role for these antibodies in joint inflammation or destruction. Therefore, researchers are 


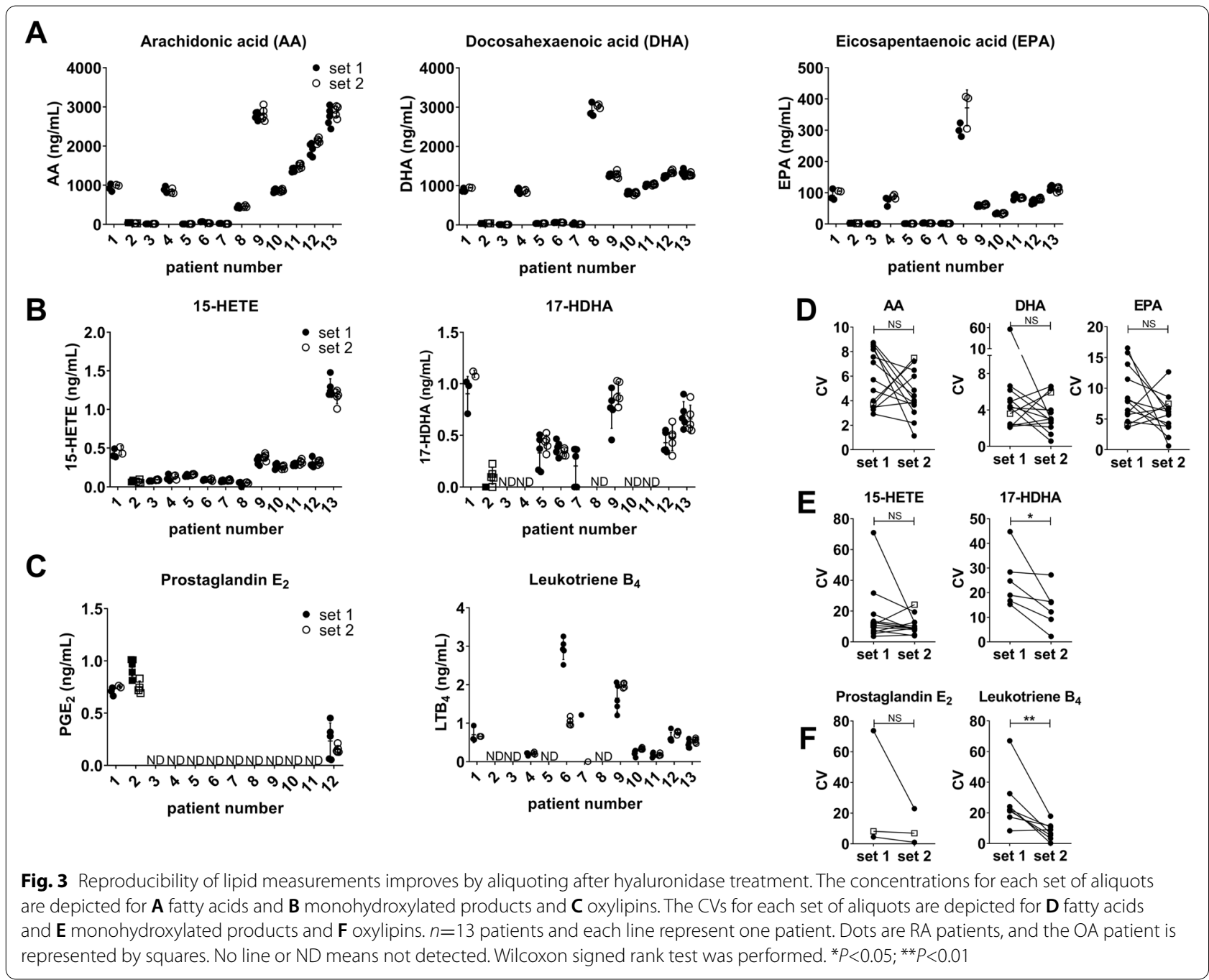

investigating presence, relative abundance, and specificity of these antibodies in the synovial fluid of, e.g., arthritis patients [33-36]. In these experiments, it is important to accurately determine the presence and specificity of autoantibodies in the joint. Our data shows that total IgG levels are not evenly distributed throughout a synovial fluid sample as measurements were less variable when taking aliquots from homogenized synovial fluid compared to when they were taken from untreated synovial fluid. We did not analyze presence or abundance of antibodies of certain specificity, but as they are present in much lower concentrations than total IgG, higher variability between aliquots might more easily result in erroneous significant differences between patient samples.

In addition to total IgG levels, 17-HDHA and pro-inflammatory $\mathrm{LTB}_{4}$ levels were also less variable when SF was aliquoted after homogenization. Although we could not show a significant reduction of $\mathrm{CVs}$ of $\mathrm{PGE}_{2}$ concentrations, as $\mathrm{PGE}_{2}$ was only detected in 3 out of 13 patients, the
3 positive patients show a similar trend as for $\mathrm{LTB}_{4}$. Fatty acid concentrations were stable between the two sets of aliquots, this could be due to a high abundance compared to oxylipins $(100-3000 \mathrm{ng} / \mathrm{mL}$ versus $0.1-1.5 \mathrm{ng} / \mathrm{mL}$ ) or better dispersion in SF as we hypothesize that the oxylipins might interact more with their environment [5].

It was shown before that reproducibility of IL-6 and IL-8 measurements in SF by multiplex (Luminex) analysis are affected by hyaluronidase treatment [31]. In contrast, we show that the reproducibility of IL-6, IL-8 and also CXCL1, IL-10, and TNF $\alpha$ measurements is equal between aliquots taken before or after hyaluronidase treatment of SF. However, this difference could easily be explained by the differences in experimental set-up. We have treated both sets of aliquots with hyaluronidase (Fig. 1A) wherease Jayadev et al. compared untreated versus treated SF. In that study, accurate measurements of IL- 6 and IL- 8 might easily be hampered by the viscousity of the SF explaining their finding. They indeed show that 


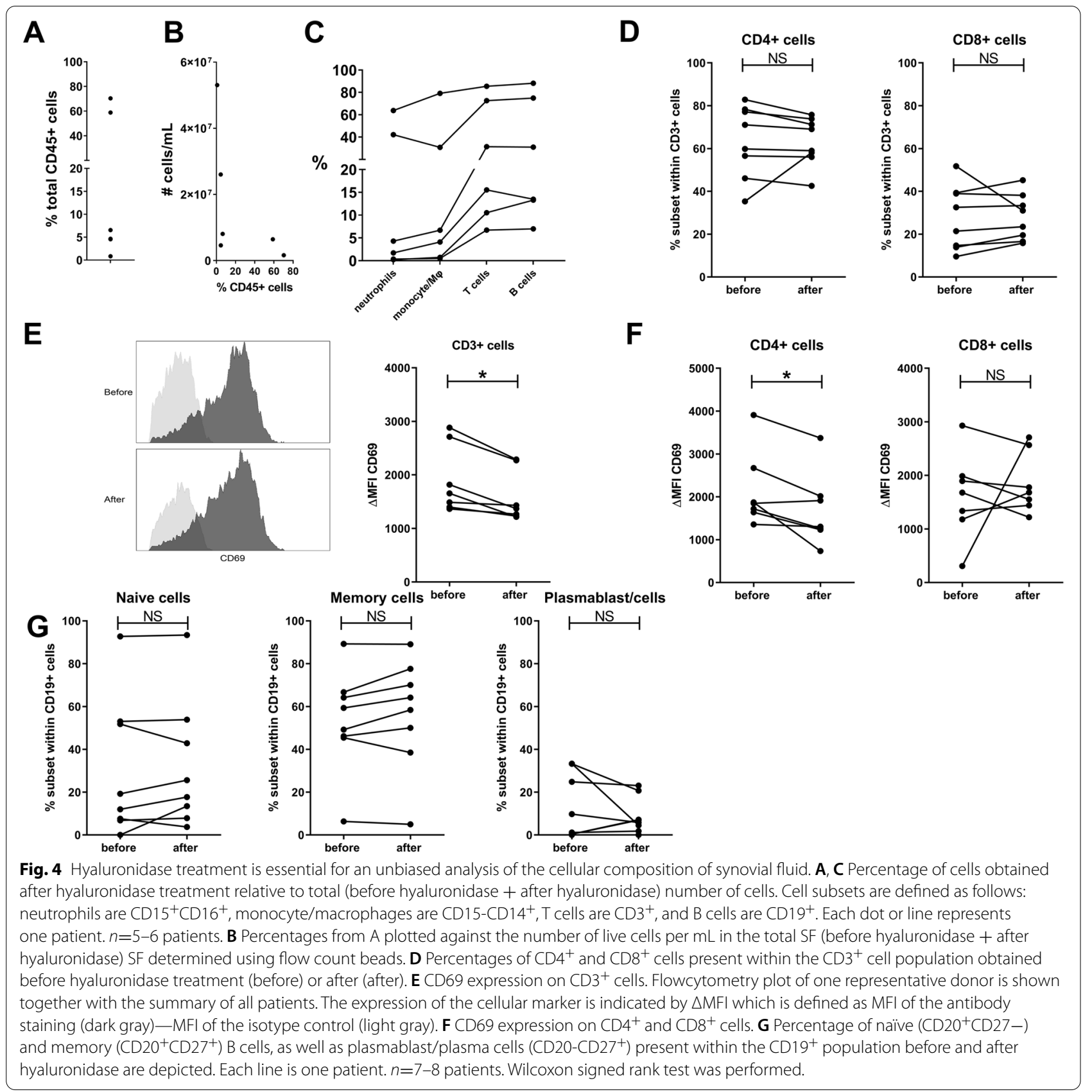

the viscosity of the untreated aliquots hampers cytokine measurements in the Luminex assay.

Since immune cells in local tissues are of great interest in understanding disease pathology, we have compared cell populations isolated from untreated and treated SF. Up to a surprisingly high percentage (70\%) of cells are often excluded from analyses when cells are isolated from untreated SF. Since specifically $\mathrm{T}$ and $\mathrm{B}$ cells are excluded, resulting data are likely highly biased. Moreover, we show that within the
$\mathrm{CD} 4^{+} \mathrm{T}$ cell populations, additional bias is introduced within the $\mathrm{CD} 69^{+}$cells. Based on our results, we hypothesize that specifically $\mathrm{T}$ and $\mathrm{B}$ cells are excluded based on their cellular size, since we could not confirm any increased interaction with the SF environment compared to other cell types. However, this hypothesis could be further tested through analysis of additional cell adhesion molecules. In addition, we could perform experiments using different sized beads to support our hypothesis of the involvement of cellular size. 


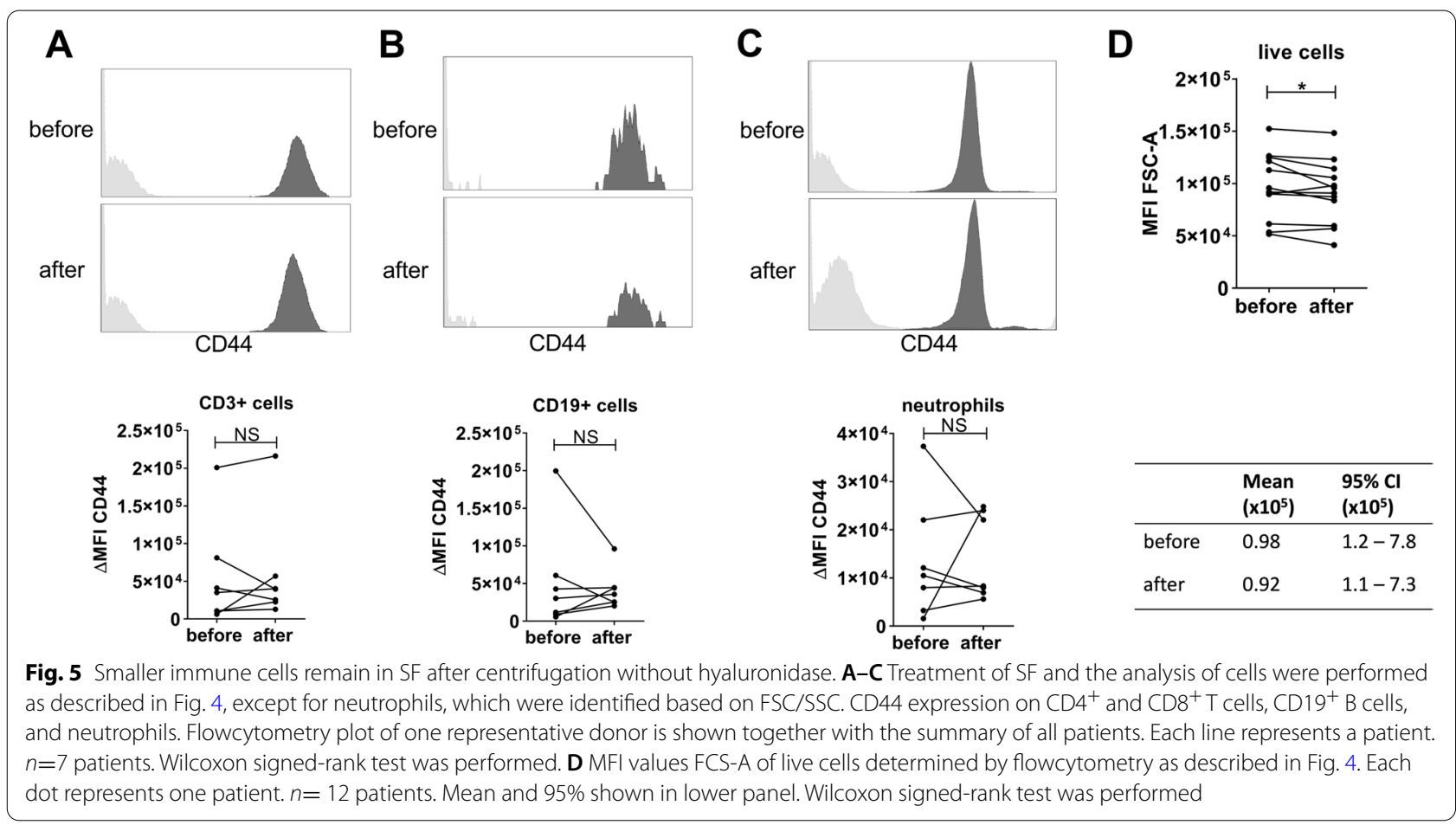

\section{Conclusions}

In summary, we show that homogenization of SF using hyaluronidase leads to less variability in oxylipin and IgG level measurements. In addition, homogenization of SF improves the recovery of immune cells during cell isolation. Based on our data, we advise researchers to perform hyaluronidase treatment on SF samples before aliquoting and subsequent analyses. Implementing hyaluronidase treatment in protocols using SF will likely result in improved reproducibility of soluble mediator measurements, new insights in the cell type ratios in joint diseases and even in the discovery of previously unidentified cell types in SF.

\section{Abbreviations}

AA: Arachidonic acid; CV: Coefficient of variation; DHA: Docosahexaenoic acid; EPA: Eicosapentaenoic acid; IL: Interleukin; JIA: Juvenile idiopathic arthritis; $\mathrm{LTB}_{4}$ : Leukotriene $\mathrm{B}_{4} ; \mathrm{OA}$ : Osteoarthritis; $\mathrm{PGE}_{2}$ : Prostaglandin $\mathrm{E}_{2}$; RA: Rheumatoid arthritis; SF: Synovial fluid; SpA: Spondyloarthritis; WBC: White blood cell.

\section{Supplementary Information}

The online version contains supplementary material available at https://doi. org/10.1186/s13075-021-02696-4.

Additional file 1: Supplementary figure 1. Gating strategy of experiments shown in Fig. 4A-C. A) Cells were gated separately from flow count beads on FSC-A/SSC-A and doublet cells were excluded by setting gates in FCS-W/FCS-H and SSC-W/SSC-H plots. Dapi staining was used to exclude dead cells and CD45+ cells were gated based on antibody staining. B) Neutrophil gates, monocyte gates and lymphocyte gates were set based on morphology on the FCS-A/SSC-A. C) The monocyte gate was plotted and contaminating CD15+ neutrophils were excluded after which CD14+ monocyte/macrophages were gated. D) The neutrophil gate is plotted and the neutrophils are characterized by CD15+ and CD16+ positivity The lymphocytes were plotted in panel $\mathbf{E}$ ) and $\mathbf{F}$ ) to be able to gate $C D 3+T$ cells and CD19+ B cells respectively based on antibody staining.

Additional file 2: Supplementary figure 2. Gating strategy of experiments shown in Fig. 4D and E. A) Flow count beads, neutrophil gates and lymphocyte gates were set based on morphology on the FCS-A/SSC-A. Doublet cells were excluded by setting gates in FCS-W/FCS-H and SSC-W/ SSC-H plots. Dapi staining was used to exclude dead cells and the live cell gate was plotted to gate CD3+ cells based on antibody staining. The CD3 + cells were further analyzed for CD4 and CD8 expression. B) Gates for Flow count beads, lymphocyte gate and single cells were set the same was a in panel A. Dead cells, CD3+ cells and CD14+ cells were excluded by gating the negative cells. These Dapi/CD3/CD14 negative cells were plotted and analyzed for CD19. CD19+ B cells were further analyzed for CD27 and CD20 to evaluate naive B cell, memory B cell and plasmablast/ plasmacell numbers.

Additional file 3: Supplementary figure 3. Hyaluronidase treatment does not effect cell marker expression. Synovial fluid was diluted 20x in PBS and divided in two. One sample was treated with hyaluronidase (treated) and the other sample was treated similar but without the addition of hyaluronidase (untreated). Cells were isolated by centrifugation and CD44 (A) and CD69 (B) expression was analyzed on various cell types in two donors (dashed versus closed line). C) Lineage marker expression is shown in two donors (stars versus dots). $\triangle \mathrm{MFl}$ is calculated using the isotype control. Wilcoxon signed rank test was performed. $n=2$ donors.

\section{Acknowledgements}

We thank all the LUMC and Alrijne patients for providing their synovial fluid for this study.

\section{Authors' contributions}

$\mathrm{HB}$ conducted the experiments, analyzed, and interpreted the data and wrote the manuscript. JH conducted some last experiments. EL included LUMC 
patients. RB included Alrijne patients. MK included LUMC patients, interpreted the data, and supervised the project. RT interpreted the data and supervised the project. MG his laboratory conducted the LC-MS/MS measurements. Al interpreted the data and supervised the project. The authors read and approved the final manuscript.

\section{Authors' information}

Not applicable

\section{Funding}

The presented research was funded by the Prof. Jan Veltkamp Fonds of the LUMC and the Dutch Arthritis Foundation.

\section{Availability of data and materials}

The datasets used and/or analyzed during the current study are available from the corresponding author on reasonable request.

\section{Declarations}

\section{Ethics approval and consent to participate}

Written informed consent was obtained from all the LUMC patients. The leftover materials of the Alrijne patients was received anonymized. The study was approved by the local ethical committee.

\section{Consent for publication}

Not applicable

\section{Competing interests}

The authors declare that they have no competing interests.

\section{Author details}

'Department of Rheumatology, Leiden University Medical Center (LUMC), Leiden, The Netherlands. ${ }^{2}$ Department of Orthopedics, Leiden University Medical Center, Leiden, The Netherlands. ${ }^{3}$ Department of Orthopedics, Alrijne Healthcare Group, Leiden, The Netherlands. ${ }^{4}$ Center for Proteomics and MetaboIomics, Leiden University Medical Center (LUMC), Leiden, The Netherlands.

Received: 14 June 2021 Accepted: 8 December 2021

Published online: 08 January 2022

\section{References}

1. Snelling SJB, Bas S, Puskas GJ, Dakin SG, Suva D, Finckh A, et al. Presence of IL-17 in synovial fluid identifies a potential inflammatory osteoarthritic phenotype. PLoS One. 2017;12(4):e0175109. [cited 2020 Aug 30]. Available from: https://www.ncbi.nlm.nih.gov/pmc/articles/PMC5388337/.

2. Altobelli E, Angeletti PM, Piccolo D, De Angelis R. Synovial fluid and serum concentrations of inflammatory markers in rheumatoid arthritis, psoriatic arthritis and osteoarthitis: a systematic review. Curr Rheumatol Rev. 2017;13(3) [cited 2020 Aug 30]. Available from: https://pubmed.ncbi.nlm. nih.gov/28460627/.

3. Mustonen AM, Käkelä R, Lehenkari P, Huhtakangas J, Turunen S, Joukainen $A$, et al. Distinct fatty acid signatures in infrapatellar fat pad and synovial fluid of patients with osteoarthritis versus rheumatoid arthritis. Arthritis Res Ther. 2019;21(1) [cited 2020 Aug 30]. Available from: https:// pubmed.ncbi.n/m.nih.gov/31118103/.

4. Giera M, Ioan-Facsinay A, Toes R, Gao F, Dalli J, Deelder AM, et al. Lipid and lipid mediator profiling of human synovial fluid in rheumatoid arthritis patients by means of LC-MS/MS. Biochim Biophys Acta Mol Cell Biol Lipids. 2012;1821(11):1415-24 [cited 2018 Jul 2]. Available from: https:// www.sciencedirect.com/science/article/pii/S1388198112001461?via\% 3Dihub.

5. Jónasdóttir HS, Brouwers H, Kwekkeboom JC, van der Linden HMJ, Huizinga T, Kloppenburg M, et al. Targeted lipidomics reveals activation of resolution pathways in knee osteoarthritis in humans. Osteoarthr Cartil. 2017;25(7):1150-60 [cited 2018 Jul 11]. Available from: https://www.scien cedirect.com/science/article/pii/S1063458417308397?via\%3Dihub\# appsec1.
6. Barden AE, Moghaddami M, Mas E, Phillips M, Cleland LG, Mori TA. Specialised pro-resolving mediators of inflammation in inflammatory arthritis. Prostaglandins Leukot Essent Fat Acids. 2016;107:24-9 [cited 2020 Aug 30]. Available from: https://pubmed.ncbi.nlm.nih.gov/27033 423/.

7. Tan LC, Mowat AG, Fazou C, Rostron T, Roskell H, Dunbar PR, et al. Specificity of T cells in synovial fluid: high frequencies of CD8+ T cells that are specific for certain viral epitopes. Arthritis Res. 2000;2(2):154-64 [cited 2020 Aug 30]. Available from:/pmc/articles/PMC17809/?report=abstract.

8. Church LD, Filer AD, Hidalgo E, Howlett KA, Thomas AM, Rapecki S, et al. Rheumatoid synovial fluid interleukin-17-producing CD4T cells have abundant tumor necrosis factor-alpha co-expression, but little interleukin-22 and interleukin-23R expression.; 2010. [cited 2020 Aug 30]. Available from: http://arthritis-research.com/content/12/5/R184

9. Schmidt T, Berthold E, Arve-Butler S, Gullstrand B, Mossberg A, Kahn F, et al. Children with oligoarticular juvenile idiopathic arthritis have skewed synovial monocyte polarization pattern with functional impairment-a distinct inflammatory pattern for oligoarticular juvenile arthritis. Arthritis Res Ther. 2020;22(1):186 [cited 2020 Aug 30]. Available from: https://arthr itis-research.biomedcentral.com/articles/10.1186/s13075-020-02279-9.

10. Yoon BR, Yoo SJ, Choi YH, Chung YH, Kim J, Yoo IS, et al. Functional phenotype of synovial monocytes modulating inflammatory T-cell responses in rheumatoid arthritis (RA). PLoS One. 2014;9(10):109775 Oct 17 [cited 2020 Aug 30]. Available from: /pmc/articles/PMC4201467/?report=abstract.

11. Jaime P, García-Guerrero N, Estella R, Pardo J, García-Álvarez F, MartinezLostao L. CD56+/CD16 - natural killer cells expressing the inflammatory protease granzyme a are enriched in synovial fluid from patients with osteoarthritis. Osteoarthr Cartil. 2017;25(10):1708-18 [cited 2018 Jul 20]. Available from: https://www.sciencedirect.com/science/article/pii/S1063 458417310555?via\%3Dihub.

12. Yamin R, Berhani O, Peleg H, Aamar S, Stein N, Gamliel M, et al. High percentages and activity of synovial fluid NK cells present in patients with advanced stage active rheumatoid arthritis. Sci Rep. 2019;9(1):1351.

13. Rao DA, Gurish MF, Marshall JL, Slowikowski K, Fonseka CY, Liu Y, et al. Pathologically expanded peripheral T helper cell subset drives B cells in rheumatoid arthritis. Nature. 2017:542(7639):110-4.

14. Bondeson J, Wainwright SD, Lauder S, Amos N, Hughes CE. The role of synovial macrophages and macrophage-produced cytokines in driving aggrecanases, matrix metalloproteinases, and other destructive and inflammatory responses in osteoarthritis. Arthritis Res Ther. 2006;8(6):R187 Available from: http://www.ncbi.nlm.nih.gov/pubmed/17177994.

15. Shen $\mathrm{H}$, Goodall JC, Hill Gaston JS. Frequency and phenotype of Thelper 17 cells in peripheral blood and synovial fluid of patients with reactive arthritis. J Rheumatol. 2010;37(10):2096-9.

16. Möttönen M, Heikkinen J, Mustonen L, Isomäki P, Luukkainen R, Lassila O. Clinical and experimental immunology 360 CD $4+C D 25+T$ cells with the phenotypic and functional characteristics of regulatory $T$ cells are enriched in the synovial fluid of patients with rheumatoid arthritis. Clin Exp Immunol. 2005;140:360-7.

17. Rosshirt N, Hagmann S, Tripel E, Gotterbarm T, Kirsch J, Zeifang F, et al. A predominant Th1 polarization is present in synovial fluid of end-stage osteoarthritic knee joints: analysis of peripheral blood, synovial fluid and synovial membrane. Clin Exp Immunol. 2018;195:395-406.

18. Moradi B, Schnatzer P, Hagmann S, Rosshirt N, Gotterbarm T, Kretzer JP, et al. CD4 + CD25 +/high CD127 low/- regulatory T cells are enriched in rheumatoid arthritis and osteoarthritis joints-analysis of frequency and phenotype in synovial membrane, synovial fluid and peripheral blood; 2014. [cited 2020 Aug 30]. Available from: http://arthritis-research.com/ content/16/2/R97

19. Newson J, Motwani MP, Kendall AC, Nicolaou A, Muccioli GG, Alhouayek $M$, et al. Inflammatory resolution triggers a prolonged phase of immune suppression through COX-1/mPGES-1-derived prostaglandin E 2. Cell Rep. 2017;20(13):3162-75 [cited 2019 Jul 7]. Available from: https://linki nghub.elsevier.com/retrieve/pii/S2211124717312585.

20. Illges H, Braun M, Peter HH, Melchers I. Reduced expression of the complement receptor type 2 (CR2, CD21) by synovial fluid B and T lymphocytes. Clin Exp Immunol. 2000;122(2):270-6 [cited 2020 Aug 30]. Available from:/pmc/articles/PMC1905766/?report=abstract.

21. Pelzek AJ, Grönwall C, Rosenthal P, Greenberg JD, McGeachy M, Moreland $L$, et al. Arthritis Rheum. 2017;69(6):1176-86. 
22. Amara K, Clay E, Yeo L, Ramsköld D, Spengler J, Sippl N, et al. B cells expressing the $\lg A$ receptor $F C R L 4$ participate in the autoimmune response in patients with rheumatoid arthritis. J Autoimmun. 2017;81:34-43. [cited 2020 Aug 30]. Available from: https://pubmed.ncbi.nlm.nih.gov/28343748/.

23. Zhao Q, Jung LK. Frequency of CD19+CD24hiCD38hi regulatory B cells is decreased in peripheral blood and synovial fluid of patients with juvenile idiopathic arthritis: a preliminary study. Pediatr Rheumatol Online J. 2018;16(1):44 [cited 2018 Jul 20]. Available from: http://www.ncbi.nlm.nih. gov/pubmed/29973221.

24. Jaime P, García-Guerrero N, Estella R, Pardo J, García-Álvarez F, MartinezLostao L. CD56+/CD16- natural killer cells expressing the inflammatory protease granzyme a are enriched in synovial fluid from patients with osteoarthritis. Osteoarthr Cartil. 2017;25(10):1708-18 [cited 2019 Oct 21]. Available from: http://www.ncbi.nlm.nih.gov/pubmed/28668542.

25. Aletaha D, Neogi T, Silman AJ, Funovits J, Felson DT, Bingham CO, et al. 2010 rheumatoid arthritis classification criteria: an American College of Rheumatology/European league against rheumatism collaborative initiative. Arthritis Rheum. 2010;62(9):2569-81 [cited 2019 Oct 22]. Available from: www.arthritisrheum.organdwww.interscience.wiley.com.

26. Aringer M, Costenbader K, Daikh D, Brinks R, Mosca M, Ramsey-Goldman $R$, et al. 2019 European league against rheumatism/American College of Rheumatology classification criteria for systemic lupus erythematosus. Ann Rheum Dis. 2019;78(9):1151-9.

27. Altman R, Asch E, Bloch D, Bole G, Borenstein D, Brandt K, et al. Development of criteria for the classification and reporting of osteoarthritis: classification of osteoarthritis of the knee. Arthritis Rheum. 1986;29(8):1039-49 [cited 2020 Aug 30]. Available from: https://pubmed.ncbi.nlm.nih.gov/3741515/.

28. Goldring SR, Goldring MB. Biology of the Normal joint. Kelley Firestein's Textb Rheumatol. 2017:1-19.e4 [cited 2018 Jul 20]. Available from: https://www. sciencedirect.com/science/article/pii/B9780323316965000012.

29. Moreno MJ, Clayburne G, Schumacher HR. Processing of noninflammatory synovial fluids with hyaluronidase for cytospin preparations improves the accuracy of differential counts. Diagn Cytopathol. 2000;22(4):256-8.

30. Ekmann A, Rigdal ML, Gröndahl G. Automated counting of nucleated cells in equine synovial fluid without and with hyaluronidase pretreatment. Vet Clin Pathol. 2010;39(1):83-9.

31. Jayadev C, Rout R, Price A, Hulley P, Mahoney D. Hyaluronidase treatment of synovial fluid to improve assay precision for biomarker research using multiplex immunoassay platforms. J Immunol Methods. 2012;386(12):22-30. https://doi.org/10.1016/j.jim.2012.08.012.

32. Mateos J, Lourido L, Fernández-Puente P, Calamia V, Fernández-López C, Oreiro $\mathrm{N}$, et al. Differential protein profiling of synovial fluid from rheumatoid arthritis and osteoarthritis patients using LC-MALDI TOF/TOF. J Proteome. 2012;75(10):2869-78 [cited 2018 Jul 20];Available from: http:// www.ncbi.nlm.nih.gov/pubmed/22245418.

33. Masson-Bessière C, Sebbag M, Durieux JJ, Nogueira L, Vincent C, GirbalNeuhauser $E$, et al. In the rheumatoid pannus, anti-filaggrin autoantibodies are produced by local plasma cells and constitute a higher proportion of IgG than in synovial fluid and serum. Clin Exp Immunol. 2000;1 19(3):544-52 [cited 2020 May 12]. Available from: http://www.ncbi. nlm.nih.gov/pubmed/10691929.

34. Naor D, Sionov RV, Ish-Shalom D. CD44: structure, function, and association with the malignant process. Vol. 71. In: Advances in cancer research: Academic Press Inc.; 1997. p. 241-319.

35. Polgár A, Falus A, Koó E, Ujfalussy I, Seszták M, Szuts I, et al. Elevated levels of synovial fluid antibodies reactive with the small proteoglycans biglycan and decorin in patients with rheumatoid arthritis or other joint diseases. Rheumatology (Oxford). 2003;42(4):522-7 [cited 2020 May 12]. Available from: http://www.ncbi.nlm.nih.gov/pubmed/12649398.

36. Willemze A, Shi J, Mulder M, Stoeken-Rijsbergen G, Drijfhout JW, Huizinga TWJ, et al. The concentration of anticitrullinated protein antibodies in serum and synovial fluid in relation to total immunoglobulin concentrations. Ann Rheum Dis. 2013;72(6):1059-63 [cited 2020 May 12]. Available from: http://www.ncbi.nlm.nih.gov/pubmed/23486413.

\section{Publisher's Note}

Springer Nature remains neutral with regard to jurisdictional claims in published maps and institutional affiliations.

Ready to submit your research? Choose BMC and benefit from:

- fast, convenient online submission

- thorough peer review by experienced researchers in your field

- rapid publication on acceptance

- support for research data, including large and complex data types

- gold Open Access which fosters wider collaboration and increased citations

- maximum visibility for your research: over $100 \mathrm{M}$ website views per year

At BMC, research is always in progress.

Learn more biomedcentral.com/submissions 